\title{
Transfusion-related acute lung injury or acute chest syndrome of sickle cell disease? - A case report
}

\author{
[Une étude de cas : lésion pulmonaire aiguë post-transfusionnelle ou syndrome
}

pulmonaire aigu de la drépanocytose?]

Paul G. Firth MBCHB,${ }^{*}$ Yoshihiko Tsuruta MD,${ }^{*}$ Yogish Kamath MD, $†$ Walter H. Dzik MD, Christopher S. Ogilvy MD, † Robert A. Peterfreund MD PhD*

Purpose: To describe how to differentiate transfusion-related acute lung injury from acute chest syndrome of sickle cell disease.

Clinical features: A neurosurgical patient with sickle cell disease received two units of packed red blood cells postoperatively. Four hours later she developed progressive respiratory distress, diffuse geographical airspace disease and bilateral pulmonary edema. The patient recovered sufficiently to be transferred from the intensive care unit within four days. The temporal relationship to transfusion, features on computerized tomographic scan, and the rapid resolution of severe edema point to a diagnosis of transfusion related acute lung injury. Granulocyte or human leukocyte antigen antibodies in donor plasma may confirm a diagnosis of transfusion injury.

Conclusion: The clinician should appreciate that erythrocyte transfusion to prevent or treat acute chest syndrome may cause transfusion related acute lung injury, a condition that mimics, exacerbates or possibly triggers the syndrome it was intended to treat.

Objectif : Décrire comment distinguer la lésion pulmonaire aiguë posttransfusionnelle et le syndrome pulmonaire aigu de la drépanocytose

Éléments cliniques : Une patiente de neurochirurgie atteinte de drépanocytose a reçu deux unités de globules rouges concentrés après l'intervention chirurgicale. Quatre heures plus tard, une détresse respiratoire, des lésions microalvéolaires diffuses et un œdème pulmonaire bilatéral se sont développés. La patiente, suffisamment remise, a pu quitter l'unité des soins intensifs en moins de quatre jours. La relation temporelle avec la transfusion, les caractéristiques de l'examen tomographique et la résolution rapide de l'œdème sévère vont dans le sens d'un diagnostic de lésion pulmonaire aiguë post-transfusionnelle. La présence, dans le sang du donneur, d'anticorps antigra- nulocytes ou antileucocytes humains peut confirmer un diagnostic de lésion post-transfusionnelle.

Conclusion : Il faut savoir que la transfusion d'érythrocytes visant à prévenir ou à traiter un syndrome pulmonaire aigu peut causer une lésion pulmonaire post-transfusionnelle, un état qui imite, exacerbe ou déclenche possiblement le syndrome qu'il voulait traiter.

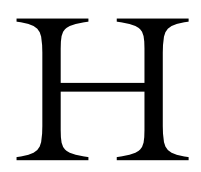

OMOLOGOUS erythrocyte transfusion is commonly performed in situations when acute chest syndrome (ACS) of sickle cell disease (SCD) may occur. Transfusion related acute lung injury (TRALI), a complication of transfusion, shares many clinical features of ACS. Although SCD patients are often transfused, TRALI has not previously been described in this population.

\section{Case report}

A 51-yr-old African-American woman with intermittent visual disturbances was scheduled for elective clipping of a 6-mm aneurysm on the ophthalmic segment of the left internal carotid artery. Past medical history was significant for homozygous hemoglobin $S$ SCD. Additional SCD-related complications included multiple pain crises, splenic infarction, leg ulceration, a pulmonary disease process diagnosed as pneumonia, chronic hepatitis C acquired from blood transfusion, and episodes of pyelonephritis. Past surgical history

From the Departments of Anesthesia and Critical Care, ${ }^{*}$ Neurosurgery, $†$ and the Blood Transfusion Service, $\ddagger$ Harvard Medical School, Massachusetts General Hospital, Boston, Massachusetts, USA.

Address correspondence to: Dr. Paul G. Firth, Nuffield Department of Anaesthetics, Radcliffe Infirmary, Woodstock Road, Oxford OX2 6HE, United Kingdom. Phone: 0186572 7342; Fax: 0186579 4191; E-mail: pfirth@partners.org

Departmental attribution: Harvard Medical School, Department of Anesthesia and Critical Care, Massachusetts General Hospital.

Financial support: administrative support and salaries of authors provided by the Massachusetts General Hospital.

Accepted for publication February 17, 2003.

Revision accepted July 21, 2003. 
included cholecystectomy, two Cesarean deliveries, two terminations of pregnancy, and leg ulcer drainage. Relevant additional history included hypothyroidism, now euthyroid on replacement L-thyroxine. Within the previous year, onset of exercise-induced dyspnea and left sided chest pain prompted pulmonary and cardiac studies. Cardiac stress testing with thallium imaging showed normal exercise capacity with no evidence of exercise-induced myocardial ischemia. The results of echocardiogram and pulmonary function tests were normal. A preoperative chest $x$-ray (CXR) was reported to show borderline cardiomegaly, with no active pulmonary disease seen. Blood results showed a hematocrit of $24 \%$, urea nitrogen of 2.5 $\mathrm{mmol} \cdot \mathrm{L}^{-1}$, and creatinine of $53 \mu \mathrm{mol} \cdot \mathrm{L}^{-1}$.

General endotracheal anesthesia was induced uneventfully. Following preoperative discussion between the surgical and anesthetic teams, hyperventilation, hypothermia and forced diuresis with mannitol and furosemide were not used. A lumbar drain was placed to facilitate surgical exposure. Central venous and direct radial arterial pressures were monitored during the case. The aneurysm, found to incorporate the origin of the ophthalmic artery, was clipped. An intraoperative angiogram demonstrated adequate collateral flow to the eye. Total blood loss was $100 \mathrm{~mL}$, replaced with $300 \mathrm{~mL}$ normal saline and 5 $\mathrm{mL} \cdot \mathrm{kg}^{-1} \cdot \mathrm{hr}^{-1}$ of maintenance fluid. Intraoperative anesthetic course was uneventful. On emergence from anesthesia and extubation, the patient was noted to be neurologically intact with the exception of an isolated left visual defect.

She was transported from the operating room to the intensive care unit in an otherwise stable condition. Lung fields were clear on CXR. It was unclear whether the unilateral visual impairment was due to traumatic neuropathy or retinal ischemia. Due to concern about potential ischemia, it was felt that correction of her chronic anemia was urgently indicated in an attempt to improve perfusion and oxygenation. Consequently, she was transfused with two units of non-leukodepleted, unwashed packed red blood cells over five hours. Retinal examination by an ophthalmologist after transfusion noted good retinal perfusion. Although perfusion may have been improved by transfusion, this retrospective finding suggests a diagnosis of traumatic neuropathy. Four hours after completion of the second transfusion, the patient began to develop increasing respiratory distress. Oral analgesic requirements for incisional pain were modest, with no complaint of extremity or chest pain. There was no hemoptysis. Physical examination noted widespread bilateral pulmonary rales, but no cardiac murmur.
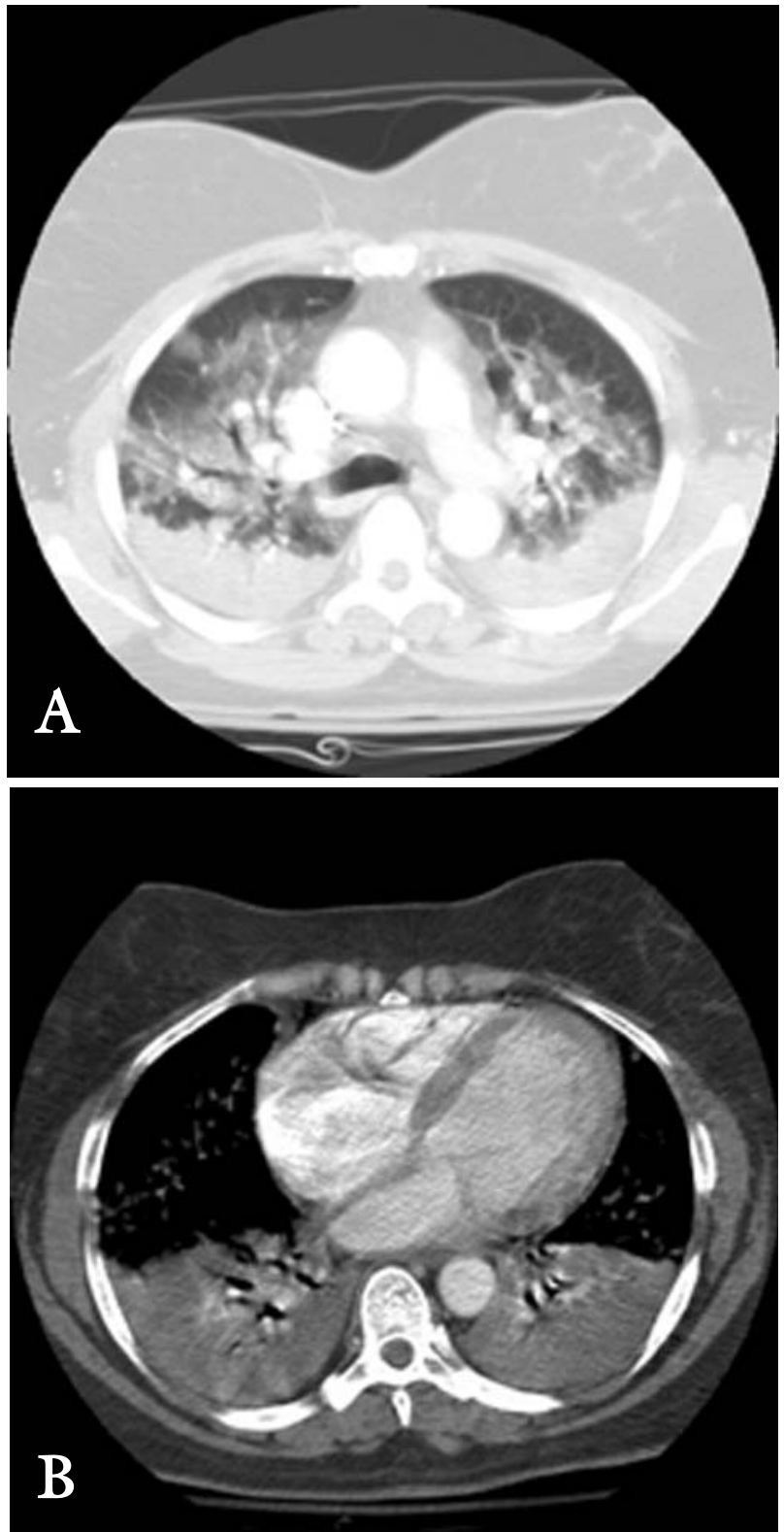

FIGURE Axial computerized tomography scan of the chest, one day after transfusion. These images demonstrate extensive bilateral parenchymal disease, and pleural effusions with adjacent atelectasis. There is no definitive evidence of a proximal intraluminal filling defect suggestive of a central pulmonary embolic disease process.

Central venous pressures were in the range of 7 to 12 $\mathrm{mmHg}$. A CXR $16 \mathrm{hr}$ post-transfusion showed increased perihilar lung density, lower lobe air bronchograms and hazy opacity of the lower lung zones at both costophrenic sulci. Pulse oximetry hemoglobin oxygen saturation was recorded as 85 to $90 \%$ despite 
an inspired oxygen fraction of $100 \%$. A contrastenhanced computerized tomography (CT) scan on postoperative day two showed dense infiltrations and air bronchograms in the dependent regions of the lower lung lobes, and multiple geographic perihilar densities consistent with focal air space consolidation. Soft tissue views showed no evidence of pulmonary embolism or infarction (Figure). CT scan of the head showed pneumocephalus and residual localized postoperative swelling. White cell count peaked at $42,300 \cdot \mathrm{mm}^{3}$, with a neutrocytosis of $92 \%$. No pathogens were isolated from blood and urine cultures. Relevant thyroid hormone studies were unremarkable. Despite the dramatic pulmonary changes on the CT scan, the patient's residual respiratory function was assessed clinically as sufficient to delay the initiation of mechanical ventilation. Management included fluid restriction, furosemide diuresis, oxygen supplementation, and incentive spirometry. Respiratory function improved rapidly over $24 \mathrm{hr}$, neutrophil count trended downwards, and she was transferred to a routine care unit on the fourth day postoperatively.

Blood bank donor samples were discarded before testing for antibodies could be performed. Subsequent enquiry revealed both blood donors were multiparous women. Extensive efforts to acquire blood samples for antibody testing were unsuccessful.

\section{Discussion}

This report documents the transient occurrence of diffuse, geographic airspace disease and pulmonary edema, accompanied by neutrophilia, arising shortly after blood transfusion, in a neurosurgical patient with SCD. The diagnosis of ACS may be suggested by a new pulmonary infiltrate involving at least one complete lung segment, consistent with the presence of alveolar consolidation, but excluding atelectasis. In addition, patients must have chest pain, a temperature of greater than $38.5^{\circ} \mathrm{C}$, tachypnea, wheezing or cough. ${ }^{1}$ TRALI may be defined as a transfusion reaction characterized variously by bilateral pulmonary edema, respiratory distress, hypoxemia, hypotension, and fever, within six hours of the transfusion of a plasma-containing blood product. ${ }^{2,3}$ Edema usually resolves within $72 \mathrm{hr}$, with appropriate respiratory support. Respiratory distress, pulmonary infiltrates on $x$-ray, and a raised white cell count seen in the present case are features common to both syndromes (Table). Surgical stress may trigger ACS, suggesting this diagnosis. However, radiographic investigations revealed a diffuse pulmonary edema. While ACS has a variable $x$ ray or CT appearance, the typical picture is one of focal consolidation of one or more lobes, with secondary pulmonary changes such as an effusion. Fat embolism from bone marrow infarction during a pain crisis may produce a diffuse pulmonary edema seen in the current case. ${ }^{1}$ However, the patient did not complain of bone pain, while the minimal postoperative analgesic requirements would be insufficient to mask extremity or chest pain. Although mild cases of ACS may resolve rapidly, severe cases may progress to the diffuse lung injury evident on the CT scan. ${ }^{1}$ Pulmonary pathology as severe as that documented in the present report would be unlikely to be transient if secondary to ACS. The temporal relationship to transfusion, the radiographic features in the absence of a fat embolism, and the rapid resolution of severe edema, point to a diagnosis of TRALI in this case. An additional possibility is the co-existence of both conditions, with ACS exacerbating or following TRALI.

The precise mechanism of TRALI is unknown, but may be an immune-mediated event. Donor antibodies, rather than recipient antibodies as in other transfusion reactions, may be the pathological trigger. ${ }^{2,3}$ Granulocyte or human leukocyte antigen (HLA) antibodies corresponding to recipient epitopes have been implicated in various studies. Infusion of donor plasma containing antibodies may activate recipient white cells to produce inflammatory mediators, leading to increased vascular permeability. Direct targeting of host pulmonary vascular endothelium by transfused donor antibodies is an additional hypothesis. Multiparous women may have an increased incidence of foreign white cell antibodies, thought to be due to exposure to fetal white cell antigens during pregnancy. Transfusion of plasma from multiparous donors may lead to a higher incidence of recipient TRALI. ${ }^{3}$ There are currently inadequate data on the pathophysiology of TRALI or possible risks posed by multiparous donors to advocate routine antibody screening or deferral of multiparous donors, however. ${ }^{3}$ An alternative theory is that a lipid mediator similar to platelet activating factor, which accumulates in stored cellular blood components, may prime recipient neutrophils to excessive response to any later inflammatory stimulus. ${ }^{4}$ Unwashed packed red blood cell units contain donor plasma that may precipitate TRALI.

Differentiation between ACS and TRALI is important for prognostic and management purposes. Progression of severe ACS may prove fatal. Mechanical ventilation, and possibly erythrocyte transfusion or exchange transfusion, may be indicated to improve oxygenation. ${ }^{1}$ In contrast TRALI has a self-limiting natural history if respiratory support is appropriate for the degree of pulmonary compro- 
TABLE

\begin{tabular}{|c|c|c|}
\hline $\begin{array}{l}\text { Condition } \\
\text { Feature }\end{array}$ & Acute chest syndrome & $\begin{array}{l}\text { Transfusion-related } \\
\text { acute lung injury }\end{array}$ \\
\hline Definition & $\begin{array}{l}\text { New pulmonary infiltrate } \\
\text { involving at least one lung } \\
\text { segment, plus chest pain, } \\
\text { fever, tachypnea, wheeze or cough. }\end{array}$ & $\begin{array}{l}\text { Acute lung injury } \\
\text { consequent on transfusion } \\
\text { Onset within six hours of transfusion }\end{array}$ \\
\hline Triggering event & $\begin{array}{l}\text { Surgical procedures } \\
\text { Infection } \\
\text { Bone pain crisis }\end{array}$ & $\begin{array}{l}\text { Transfusion of plasma } \\
\text { containing blood products }\end{array}$ \\
\hline $\begin{array}{l}\text { Clinical features } \\
\text { (variable for both syndromes) }\end{array}$ & $\begin{array}{l}\text { Acute respiratory distress } \\
\text { Fever }(80 \%) \\
\text { Chest pain }(45-60 \%) \\
\text { Leukocytosis }(70 \% \text { increase on baseline }) \\
\text { Prior limb pain }(10-50 \%) \\
\text { Typical duration seven days } \\
\text { Mortality } 3 \%\end{array}$ & $\begin{array}{l}\text { Acute respiratory distress } \\
\text { Fever } \\
\text { Hypotension } \\
\text { Leukocytosis } \\
\text { Typical duration } 72 \mathrm{hr} \\
(80 \%) \\
\text { Mortality } 5-10 \%\end{array}$ \\
\hline Radiographic features & $\begin{array}{l}\text { Variable presentation: } \\
\text { Isolated lobe involvement }(60-75 \%) \\
\text { Multilobe involvement }(25-40 \%) \\
\text { Pulmonary embolism } \\
\text { Pulmonary infarction } \\
\text { Pleural effusion }(20-55 \%) \\
\text { May have bilateral pulmonary edema. }\end{array}$ & $\begin{array}{l}\text { Bilateral pulmonary edema, } \\
\text { initially patchy progressing to diffuse edema } \\
\text { Unilateral or strictly } \\
\text { localized lung pathology is uncharacteristic }\end{array}$ \\
\hline Donor antibodies & Not applicable & $\begin{array}{l}\text { Class I or II HLA-specific or } \\
\text { granulocyte antibodies present } \\
\text { in } 85 \% \text { of cases }\end{array}$ \\
\hline
\end{tabular}

Transfusion related acute lung injury (TRALI) may be diagnosed by the exclusion of clinical or radiological features specific to acute chest syndrome (ACS), and a temporal relationship to transfusion. Donor antibodies are detectable in most but not all cases of TRALI. TRALI and ACS may, however, co-exist following transfusion in settings when ACS may occur. Additional potential causes of cardiogenic and non-cardiogenic edema include acute myocardial dysfunction, fluid overload, valvular dysfunction, neurogenic pulmonary edema, aspiration pneumonia, pulmonary embolism or infarction, radiographic contrast allergy, anaphylaxis, hypothyroidism, and adult respiratory distress syndrome. These differential etiologies should be excluded before a diagnosis of ACS or TRALI can be made.

mise. ${ }^{2,3}$ The diagnosis of TRALI may be aided by screening donor plasma for granulocyte or HLA antibodies. However, limited availability of testing, the time taken to obtain the screen, as well as reported cases of TRALI occurring without positive antibody screen, mean that TRALI is predominantly a clinical diagnosis. An additional interesting feature of the present case is the apparent discrepancy between the clinical pulmonary findings and the severity of lung injury noted on radiological investigation. Other authors have made similar observations. ${ }^{2,5}$ It is unclear if this represents a unique feature of the lung injury caused by TRALI, or if these are simply chance anecdotes.

The present report emphasizes that the clinician should carefully balance the benefits and risks of transfusion. Correction of anemia is a potential indication for transfusion of patients with SCD. As our patient was at her chronic baseline anemia preoperatively, and intraoperative blood loss was minimal, oxygen delivery was assessed as adequate for the procedure. Although the intra-operative angiogram and retinal examination suggest acute ischemia was not the cause of the blindness, our uncertainty as to the diagnosis triggered the decision to transfuse the patient postoperatively. Unfortunately the subsequent course illustrates the dangers of transfusion. SCD patients have an increased incidence of red cell alloimmunization, or host sensitization to non-ABO donor erythrocyte antigens, following homologous transfusion. ${ }^{6}$ The mechanism for this is unclear. Possible pre-existing immune dysfunction may be related to host erythrocyte membrane disruption. ${ }^{7}$ Host immune reaction to donor antigens may therefore be abnormal. ${ }^{8}$ In contrast to red cell alloimmunization, TRALI may be mediated by host white cells stimulated by donor antibodies. ${ }^{2,3}$ However, neutrophil function, ${ }^{9}$ as well as vascular endothelial biology, ${ }^{10}$ is abnormal in SCD. Prior activation of neutrophils or pulmonary endothelial damage may predispose to TRALI following subsequent transfusion. ${ }^{6}$ Thus, in addition to erythrocyte antigen reactions, SCD patients may also, potentially, be more susceptible to severe forms of neutrophil- 
mediated acute lung injury. ${ }^{11}$ The clinician should therefore have a heightened concern for transfusion complications in patients with SCD.

Additional possible indications for transfusion include the prevention or treatment of perioperative SCD complications such as ACS. The role of erythrocyte transfusion in the prevention or treatment of ACS remains unclear. ${ }^{12}$ The efficacy of prophylactic transfusion to prevent postoperative ACS has not been demonstrated by a prospective randomized trial. Consequently we elected not to transfuse this patient preoperatively. Similarly, while observational studies suggest transfusion may improve oxygenation in severe ACS, ${ }^{1,13,14}$ prospective studies demonstrating improved outcome are absent. As transfusion is typically performed in situations where ACS may occur or is already present, TRALI may be unrecognized and pulmonary complications instead erroneously attributed to ACS. TRALI may imitate, exacerbate and perhaps precipitate ACS. Caution should therefore be exercised in the use of a treatment for ill-defined indications, when a complication of that intervention is a syndrome that mimics, worsens or possibly triggers the condition it is intended to treat.

\section{References}

1 Vichinsky EP, Neumayr LD, Earles AN, et al. Causes and outcomes of the acute chest syndrome in sickle cell disease. National Acute Chest Syndrome Study Group. N Engl J Med 2000; 342: 1855-65.

2 Popovsky MA, Moore SB. Diagnostic and pathogenetic considerations in transfusion-related acute lung injury. Transfusion 1985; 25: 573-7.

3 Popovsky MA, Davenport RD. Transfusion-related acute lung injury: femme fatale? (Editorial). Transfusion 2001; 41: 312-5.

4 Silliman CS. Transfusion-related acute lung injury. Transfus Med Rev 1999; 13: 177-86.

5 Ward HN. Pulmonary infiltrates associated with leukoagglutinin transfusion reactions. Ann Intern Med 1970; 73: 689-94.

6 Cox JV, Steane E, Cunningham G, Frenkel EP. Risk of alloimmunization and delayed hemolytic transfusion reactions in patients with sickle cell disease. Arch Intern Med 1988; 148: 2485-9.

7 Petz LD, Yam P, Wilkinson L, Garratty G, Lubin B, Mentzer $W$. Increased IgG molecules bound to the surface of red blood cells of patients with sickle cell anemia. Blood 1984; 64: 301-4.

8 Castellino SM, Combs MR, Zimmerman SA, Issitt PD, Ware RE. Erythrocyte autoantibodies in paediatric patients with sickle cell disease receiving transfusion therapy: frequency, characteristics and significance. $\mathrm{Br} \mathrm{J}$
Hematol 1999; 104: 189-94.

9 Lard LR, Mul FP, de Haas M, Roos D, Duits AJ. Neutrophil activation in sickle cell disease. J Leukoc Biol 1999; 66: 411-5.

10 Hebbel RP, Vercellotti GM. The endothelial biology of sickle cell disease. J Lab Clin Med 1997; 129: 288-93.

11 Hsu L, McDermott T, Brown L, Aguayo SM. Transgenic HbS mouse neutrophils in increased susceptibility to acute lung injury. Implications for sickle acute chest syndrome. Chest 1999; 116(2 Suppl): 92S.

12 Esseltine DW, Baxter MR, Bevan JC. Sickle cell states and the anaesthetist. Can J Anaesth 1988; 35: 385-403.

13 Emre U, Miller ST, Gutrierez M, Steiner P, Rao SP, Rao $M$. Effect of transfusion in acute chest syndrome of sickle cell disease. J Pediatr 1995; 127: 901-4.

14 Mallouh $A$ A, Asha $M$. Beneficial effects of blood transfusion in children with sickle cell chest syndrome. Am J Dis Child 1988; 142: 178-82. 